\title{
Land Degradation of the Mau Forest Complex in Eastern Africa: A Review for Management and Restoration Planning
}

\author{
Luke Omondi Olang ${ }^{1}$ and Peter Musula Kundu ${ }^{2}$ \\ ${ }^{1}$ Department of Water and Environmental Engineering, \\ School of Engineering and Technology, Kenyatta University, Nairobi, \\ ${ }^{2}$ Department of Hydrology and Water Resources, \\ University of Venda, Thohoyandou, \\ ${ }^{1}$ Kenya \\ ${ }^{2}$ South Africa
}

\section{Introduction}

The Mau Forest Complex is the largest closed-canopy montane ecosystem in Eastern Africa. It encompasses seven forest blocks within the Mau Narok, Maasai Mau, Eastern Mau, Western Mau, Southern Mau, South West Mau and Transmara regions. The area is thus the largest water tower in the region, being the main catchment area for 12 rivers draining into Lake Baringo, Lake Nakuru, Lake Turkana, Lake Natron and the Trans-boundary Lake Victoria (Kundu et al., 2008; Olang \& Fürst, 2011). However, in the past three decades or so, the Mau Forest Complex (MFC) has undergone significant land use changes due to increased human population demanding land for settlement and subsistence agriculture. The encroachment has led to drastic and considerable land fragmentation, deforestation of the headwater catchments and destruction of wetlands previously existing within the fertile upstream parts. Today, the effects of the anthropogenic activities are slowly taking toll as is evident from the diminishing river discharges during periods of low flows, and deterioration of river water qualities through pollution from point and non-point sources (Kenya Forests Working Group [KFWG], 2001; Baldyga et al., 2007). Augmented by the adverse effects of climate change and variability, the dwindling land and water resources has given rise to insecurity and conflicts associated with competition for the limited resources. It is hence becoming urgently important that renewed efforts are focused on this region to avail better information for appropriate planning and decision support.

Such a process will nonetheless, require an integrated characterization of the changing land and water flow regimes, and their concerned socio-economic effects on resource allocation and distribution (Krhoda, 1988; King, et al., 1999). Assessing the impacts of the environmental changes on water flow regimes generally require provision of time series meteorological, hydrological and land use datasets. However, like in a majority the developing countries, the MFC does not have good data infrastructure for monitoring purposes (Corey et al., 2007; Kundu et al., 2008). A majority of research studies in the area 
have relied on low resolution land cover datasets, including approximate physically-based procedures to understand the space and time surface alterations. Renewed efforts are thus underway in the MFC at present in order to avail high resolution information to be used for updating the existing databases with a view of improving future forecasts for restoration management as shown in Figure 1. Datasets from relevant research organization such as the World Agro-forestry Centre (ICRAF), Regional Centre for Mapping of Resources for Development (RCMRD), Regional Disaster Management Center of Excellence (RDMCOE) and IGAD - Climate Prediction and Application Centre (ICPAC) are hence being harmonized for use in evaluating the environmental effects of spatial changes, especially within hotspot regions of the complex. Cost effective computer-based techniques, which can efficiently analyze diverse physically-based variables are also under consideration to enhance the application of appropriate distributed-based management interventions (Kundu, 2007; Olang, 2009).

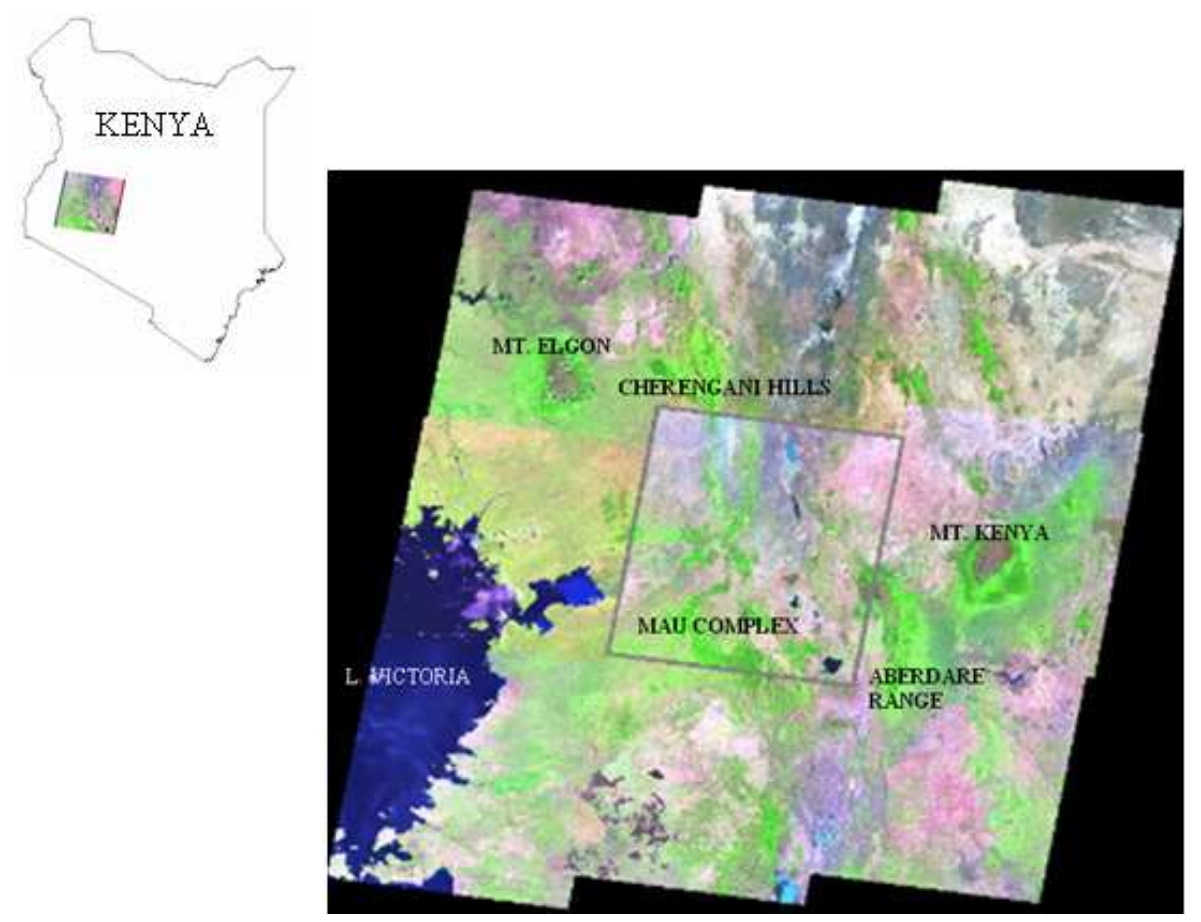

Fig. 1. Location of the five water towers of Kenya, including the MFC region (Mosaiced images of Landsat 2000).

Furthermore, with continued advancements in global remote Sensing (RS) and GIS monitoring techniques, it is increasingly becoming possible to evaluate detailed land cover change trajectories for improved resource management. Relevant contemporary alternatives such as automated extraction of geomorphologic and hydrologic properties from satellite derived Digital Terrain Models (DEM) can thus be undertaken as viable tools for model based simulation of relevant catchment-based properties. Already, there is a general consensus that for such spatial models to be used for successive impact analyses and decision support, the 
results should provide detailed information with a good degree of confidence, and where possible, validated through a participatory approach involving ground measurements and indigenous knowledge (Liu et al., 2004; Refsgaard \& Henriksen, 2004; Rambaldi et al., 2007).

Generally, most of the existing studies in the MFC were carried-out at catchment-scales with a view to determine the hydrological impacts of the environmental changes. Studies that catalog the land cover alterations to provide time-series trajectories for continued update of the existing water resources master plans are very few. In fact, the existing efforts are often isolated, unpublished and difficult to access to enhance synergistic research geared towards dependable restoration management. In this contribution therefore, the general ecology and deforestation patterns of the MFC are reviewed with the aim of consolidating and documenting the scattered information important for hinging the development of improved tools for sustainable land and water resource management. Emphasis is placed on the findings of previous works employed to monitor surface alterations as a fundamental component of land degradation in the susceptible MFC.

\section{Environmental changes and land cover degradation}

Environmental changes arise from the fact that most natural and artificial earth surface features are in a state of flux. The rate of these changes is quite often not uniformly distributed, but depends rather on the interactions of the biophysical and human components (Coppin et al., 2004; Jensen, 2005). The need for resource sustainability through proper management has today prompted timely and accurate monitoring of environmental changes to understand their relationships and interactions within a given ecosystem. However, monitoring environmental changes requires a deep understanding of the relevant environmental attributes over time and space to avoid simplistic representations. Common examples of environmental changes largely witnessed today in the developing countries include changes in forest characteristics due to human induced deforestation processes, ecological changes due to the need for agricultural expansion and land use/land cover changes due to factors related to human influences from increased population (Pellikka et al., 2004; Corey et al., 2007). In the last couple of years, significant attention has been given to land use and land cover changes, since they form a major component of global changes with greater impact than that of climate change (Foody, 2001; Olang et al., 2011). Such changes in land cover can be generally differentiated into land cover modification and land cover conversion. Land cover modification generally refers to the full substitution of one cover type by another, as is the case with urbanization.

In a majority of developing countries, land cover conversion which refers to gradual changes affecting the nature of the land cover but not their overall classifications are common. Such conversions may arise from the natural resilience of an ecosystem due to climatic variability and/or from complex land cover changes due to direct or indirect anthropogenic factors. Specifically in the MFC, both land cover modifications and conversions are predominant, and are largely attributed to the increasing human population pressure demanding more land for settlement, pasture and agriculture. This is further aggravated by the dire need for economic sustainance from the within vicinity natural resources without taking into account proper land use management practices. Forest degradation through charcoal burning followed by conversion of the deforested areas into subsistence agriculture is widespread in the headwaters catchments. In addition to this are the uncontrolled cattle grazing, slash and burn farming methods in the midland areas. With 
continued diminishing economic alternatives for the rural population, more farms are being put under small scale subsistence agriculture to provide a means of a living for the riparian communities living in the forest complex.

\section{The Mau forest complex}

\subsection{Physiography and geology}

The major geomorphological features of the forest complex comprise of the escarpments, hills, rolling land and plains (Figure 2). The topography is predominantly rolling land with slopes ranging from $2 \%$ in the plains to more than $30 \%$ in the foothills. Geological studies have shown that the area is mainly composed of quaternary and tertiary volcanic deposits (Sombroek et al., 1980). The quaternary deposits include pyroclastics and sediments, and largely cover the Northern part of the complex. Tertiary deposits predominate in the southern parts, and include black ashes and welded tuffs. From field-measurements, the top soils in the plains are of clay loam (CL) to loam (L) in texture, with friable consistence and weak to moderate sub-angular blocky structure. The subsoil texture ranges from silty clay loam (SCL) to clay loam (CL) and clay (C), with $\mathrm{pH}$ values ranging from 5.6 to 6.4 , making them slightly to moderately acidic in nature (China, 1993). In the upland areas however, the soils are largely of high content of silt and clay consequent of Ferrasols, Nitisols, Cambisols and Acricsols according to the Food and Agricultural Organisation of the United Nations (FAO-UN) soil classification procedure (World Soil Information [ISRIC]/FAO-UN, 1995). In the lowland, Luvisol, Vertisol, Planosol, Cambisol and Solonetz soils from the Holocene sedimentary deposits are primarily prevalent and occur in saline and sodic phases.

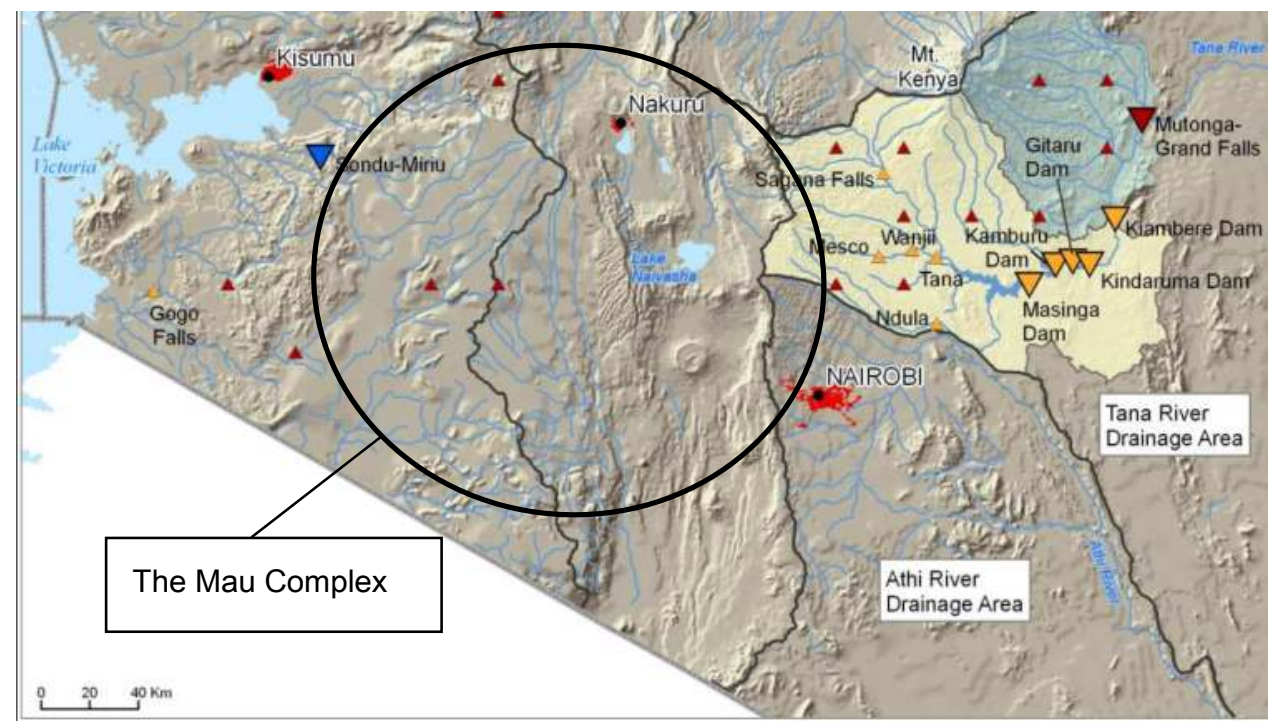

Fig. 2. Physical features, including the drainage network of the Mau Forest Complex (World Resources Institute, 2007).

Similar trends in the soil and geological characteristics of the area were also achieved with processed soils data obtained from the Global Environment Facility Soil Organic Carbon 
(GEFSOC) project (FAO-UNESCO, 1998; Batjes \& Gicheru, 2004). This dataset is available at a scale of 1:1M for Kenya, and is a modification of the original SOTER soils data of the International Society of Soil Science (ISSS). Other hydrological studies of the headwaters of the MFC have employed remotely sensed datasets to derive the geomorphological characteristics of the region (Kundu, 2007; Baldyga et al., 2007). A 3-Arc second grid based digital elevation model (DEM) acquired from the Shuttle Radar Topographic Mission was used in this context. Through computer aided procedures in a GIS, a raster analysis was performed to generate stream directions and networks, which matched very closely with the actual drainage patterns.

\subsection{Climate}

\subsubsection{Rainfall}

The climate of the Mau complex is largely influenced by the North - South movement of the Inter-tropical Convergence Zone (ITCZ) modified by local orographic effects. In terms of seasonality, the complex can be classified as trimodal, with the long rainy season predominant between the months of May and June and the short rainy season prevalent between the months of September and November. Generally, the complex receives an average annual rainfall of about $1300 \mathrm{~mm}$ on normal years devoid of climatic extremes such as the El Niño Southern Oscillation (ENSO). Mean monthly rainfall events in the range of 30 $\mathrm{mm}$ to over $120 \mathrm{~mm}$ are common (Figure 3).

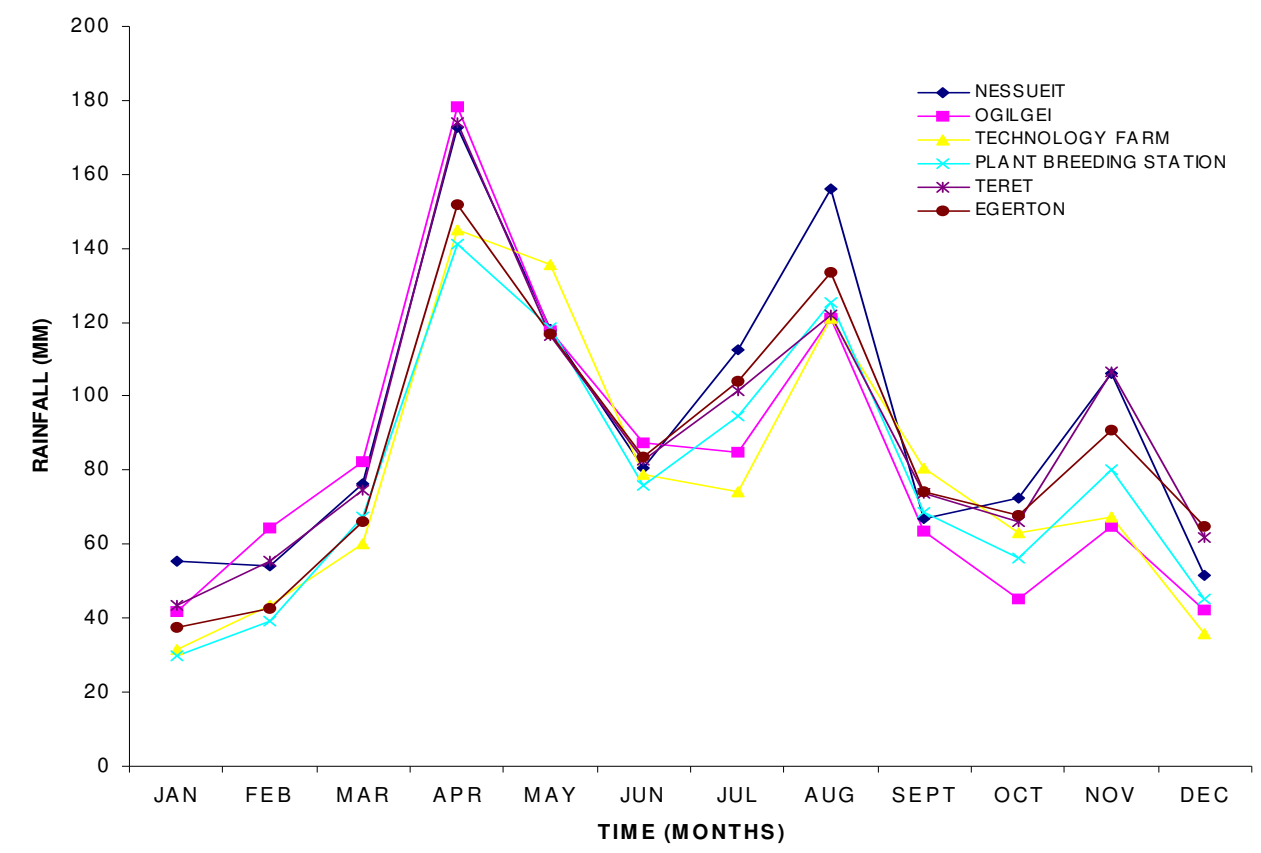

Fig. 3. Monthly rainfall distribution from six selected weather stations within the Mau Complex (Kundu, 2007).

There are a few pluviometric stations in the complex where quality rainfall data can be obtained from. However, due to the diverse topography of the area, the existing gauge 
density can be considered not sufficient for distributed representation of rainfall induced process. This coupled with uncertanities related to measurement errors and missing data, recent developments by the Kenya Meteorological Department have considered the use of satellite based rainfall estimates (RFE) such as the Tropical Rainfall Measuring Mission (TRMM) for concerned impact studies especially in large areas. In small areas however, RFE require regionalisation through calibration with observed point data to derive region-based adjustment coefficients (Borga, 2000; Krajewski et al., 2002).

\subsubsection{Temperature and evapo-transpiration}

The Mau Forest Complex generally falls in agro-climatic zones I, II and III when classified according to moisture-indices obtained from average evapo-transpiration rates and annual rainfall amounts. Because of its varied topography, estimation of the actual mean air temperatures for the whole area is often quite complicated. However, based on altitude zones, the monthly air temperature estimates for the basin are as provided in Table 1.

\begin{tabular}{ccccc}
\hline \multirow{2}{*}{$\begin{array}{c}\text { Altitude Zone } \\
(\mathrm{m})\end{array}$} & \multicolumn{2}{c}{ Mean monthly air temperatures $\left({ }^{\circ} \mathrm{C}\right)$} & \multirow{2}{*}{$\begin{array}{c}\text { Abs. minimum } \\
\text { temp. }\left({ }^{\circ} \mathrm{C}\right)\end{array}$} \\
\cline { 2 - 4 } & Maximum & Minimum & Mean & $10-13$ \\
\hline $1100-1300$ & $27-30$ & $15-17$ & $21-23$ & $9-11$ \\
$1300-1500$ & $27-29$ & $13-15$ & $20-22$ & $6-9$ \\
$1500-2000$ & $22-28$ & $10-13$ & $17-20$ & 6 \\
\hline
\end{tabular}

Table 1. Mean Annual air temperature ranges for different altitude zones

For estimation of localised evapo-transpiration rates, a majority of studies have employed empirical models that incorporate both physical and aerodynamic parameters. The most predominant due to its ability to closely approximate the crop reference evapo-transpiration $\left(\mathrm{ET}_{\mathrm{o}}\right)$ rates is the FAO Penman-Monteith method (FAO, 1998, 2009). In many cases, the average evapotranspiration of the complex are estimated in relation to the existing land use types. In the entire complex, annual average estimates between $1.3 \mathrm{~mm} /$ day to $4.2 \mathrm{~mm}$ /day, with an average of about $3.85 \mathrm{~mm} /$ day, have been recorded. The ETo has also been noted to increase with mean annual rainfall amounts, confirming that the complex is water stressed. The results are also consistent with the reduced infiltration rates owing to the loss of much of the vegetative cover in the area (Owido et al., 2003).

\subsection{Hydrology}

\subsubsection{Drainage and stream network}

The Mau Complex is drained mainly by 12 rivers including Rivers Njoro, Molo, Nderit, Makalia, Naishi, Kerio, Mara, Ewaso Nyiro, Sondu, Nyando, Yala and Nzoia. Space and time variations of the stream flows are normally influenced by the morphometry, lithology, land use/cover and rainfall patterns. Normally, the stream flow characteristics are potential indicators of the hydrological status of a region (Calder, 1998). In the last three decades, physical evidence has revealed that the rivers in the MFC have had significant decline in discharges, coupled by dwindling water quality. Other studies have also highlighted the changing hydrological response of the area consequent of the land use/land cover changes (Kundu et al., 2000; Owido et al., 2003). However, the effects associated with climate change cannot be fully ignored in this context as well.

So far, a majority of studies carried out in the MFC have focused more at catchment scales. It will be thus imperative to develop procedures that can be used to asses the hydrological 
water quality and quantity in the entire forest complex. Considering the weak infrastructural capacities, and hence the poor data quality, the application of remotely sensed datasets provides a great potential in monitoring and management of the area. Conventional Radio Detecting and Ranging (RADAR) based techniques for rainfall and moisture content estimation can be explored in this respect. A reliable and integrated database built in a GIS, can also be used to address various issues related to data management, especially for dependable land and water resource planning. Today, global datasets about surface elevation and land cover characteristics can be freely acquired to enhance simulation studies. Typical synthetic drainage network can equally be derived from Digital Elevation Models (DEM) of the area. Figure 4 illustrates the integration of RS and GIS that could be used for managing the MFC by using freely acquired images. The results generally compared well to the reality despite the medium resolution of the images. With further processing, supported by secondary datasets from high resolution satellite images, it is possible to improve the quality of the derived stream-networks.

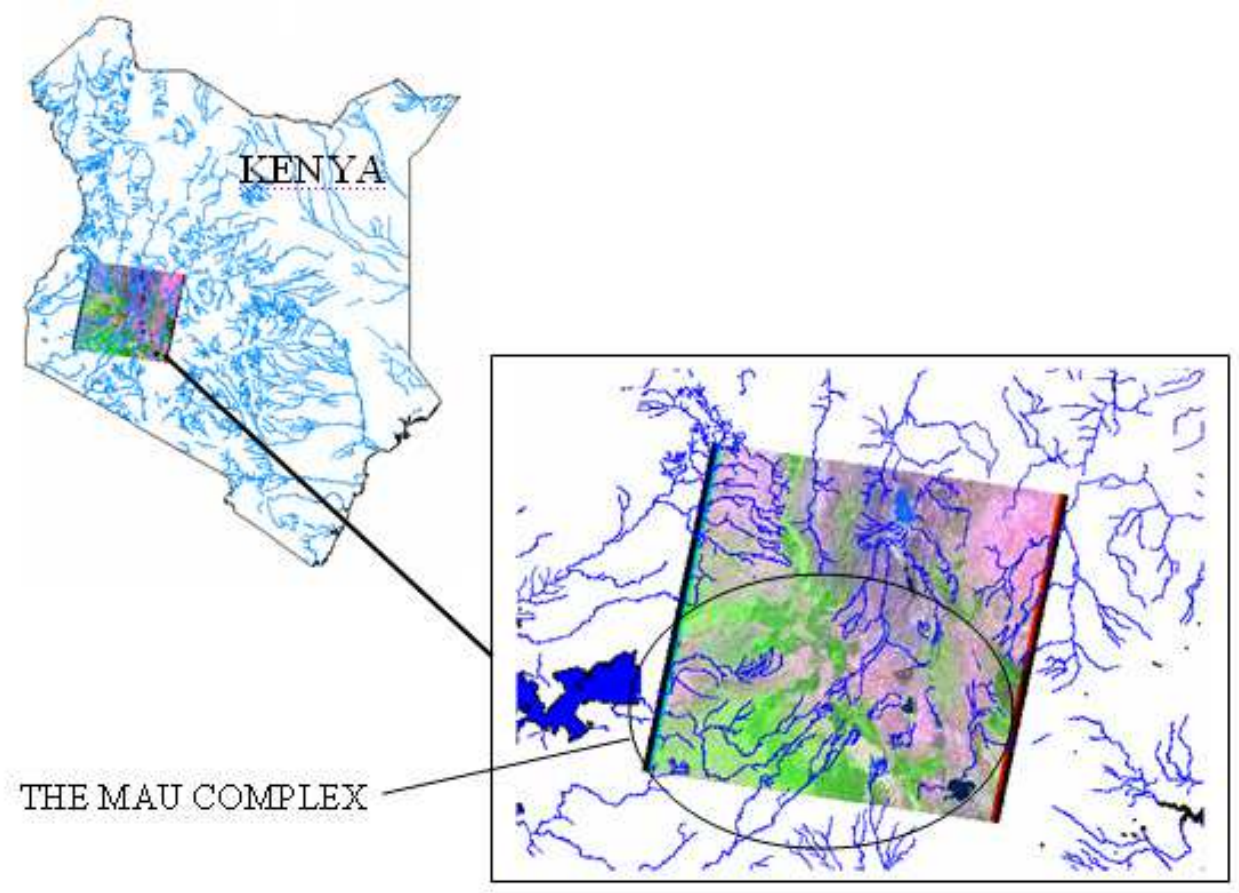

Fig. 4. Drainage network within the Mau Forest Complex.

\subsubsection{Velocity and discharge}

Normally, to elucidate the mechanisms driving discharge variability, a study period of not less than 30 years is usually recommended. This period is considered long enough to discern effects consequent of either land use changes or climate change and variability. Land use change effects are commonly investigated by understanding the discharge regimes during rainy seasons especially. Depending on the magnitude of the spatial changes however, 
utmost care must be taken since studies in Kenya have also shown that the effects of land cover change on runoff events tend to diminish with increased magnitude of storm events (Olang \& Fürst, 2011). Chemelil (1995) and Kundu et al. (2008) assessed the mean rainfall and discharge characteristics of the Njoro River located in Eastern Mau to understand the influence of environmental changes in the area. The authors used a similar procedure provided by Marcos et al. (2003). The results obtained are illustrated in Figure 5.

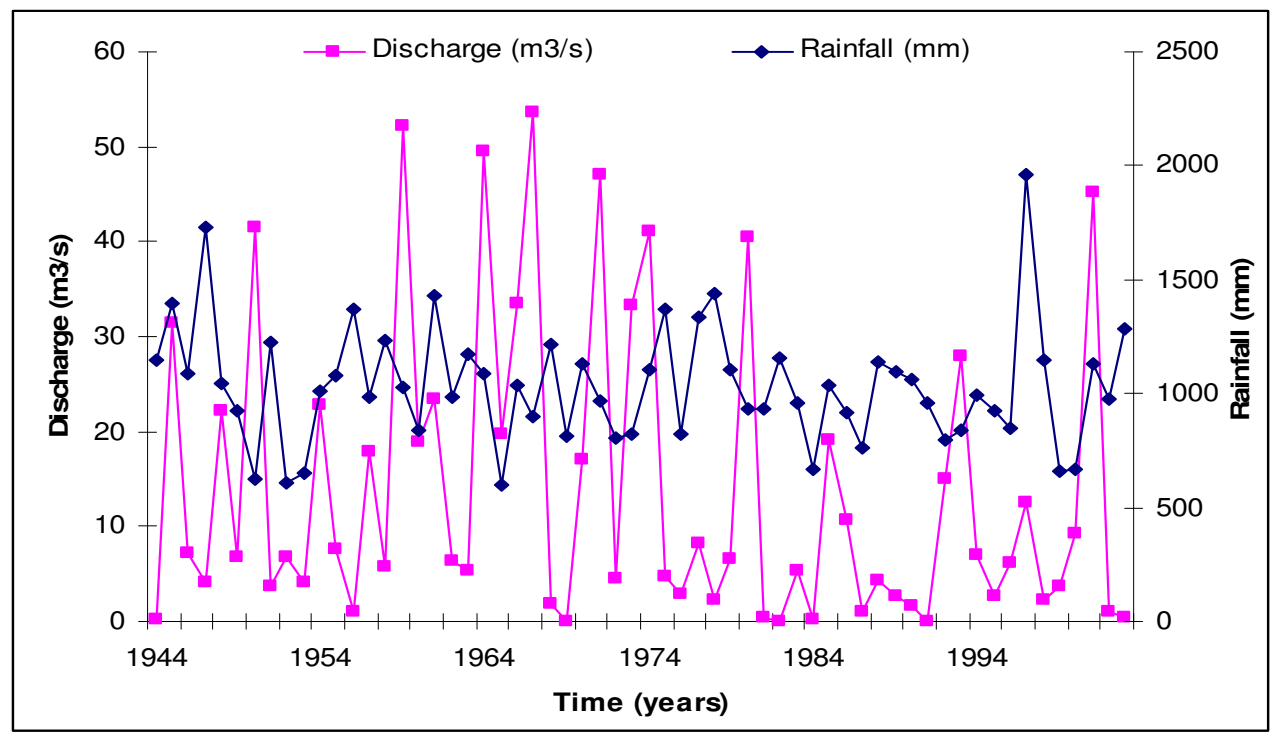

Fig. 5. Long-term annual rainfall and discharge relationship between 1944 and 2001.

From the figure, discharges in the area showed a decreasing trend against a rather consistent rainfall pattern. The frequency of low flow was noted to have increased, especially in the interval between 1980 and 2000. This trend was largely attributed to the changing land use patterns, considering that this period witnessed the highest human encroachment within the MFC. It was hence more likely that the unplanned conversion of forest and woodlands into agriculture and built up area within the headwaters could have influenced the discharge generation processes and hydrological regimes of the area. Other reasons associated with this were increased water abstraction for irrigation and domestic purposes consequent of the rising population.

\subsection{Land cover and land use}

The Mau complex has the largest indigenous montane forest covering an area of about 2700 $\mathrm{km}^{2}$ at present. Vegetation in the area varies largely from grasslands with scattered trees in the plains, to shrubland and forests in the hilly uplands. In the higher mountain ranges, bamboo forests are largely predominant. The vegetation around the rivers and lakes mainly comprises of acacia trees and dense bush and shrubs. The escarpments are mainly wooded and bushy with a wide ecological diversity. The higher areas comprise of forests with acacia xanthophloea, Olea hochstetteri, Croton dichogamus, euphorbia candelabrum forest and bush land. Previously, the area was largely covered by rich evergreen forests, extending from the 
highlands of Mau hills, and woodland dominated by acacia trees in the plains. A Landsat image (P169R60) in bands 4-3-2 for February 2000 showing the predominant vegetation and land cover of the Mau complex are provided in Figure 6. The continuous deep red represents highland vegetation on the escarpments and hill ranges. The green-blue patches largely represent open pasture and grassland, bare soil, roads, built-up areas and farms after harvesting.

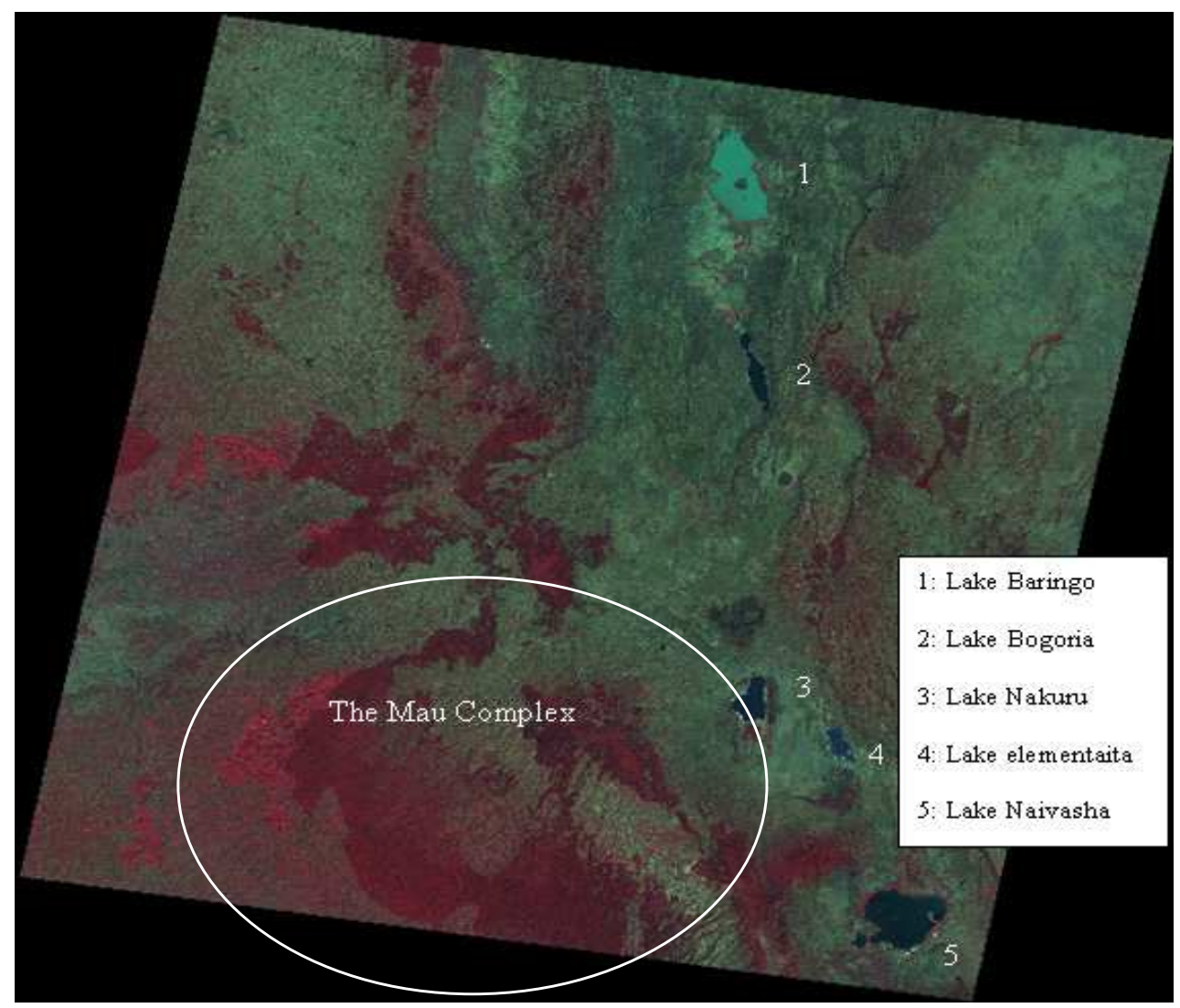

Fig. 6. Landsat image for February 2000 showing Land cover and Rift Valley lakes.

Within the blocks of the MFC, the eastern Mau has witnessed most of the land use changes consequent of the up-surging human population and their associated activities. The former large scale farms have been subdivided and allocated to small scale farmers. For instance, the former Sebiens (Ngondu) and Wright (Njokerio) large scale farms, which produced flowers, wheat and dairy products on commercial basis, have been converted into small arable and grazing plots through the land fragmentation process. In Baruti area near Lake Nakuru, a lunar landscape with the potential for landslide disasters during storm events has been created by the haphazard and unplanned sand mining and quarrying activities carried out in the area (Figures 7 (a) and (b)). 


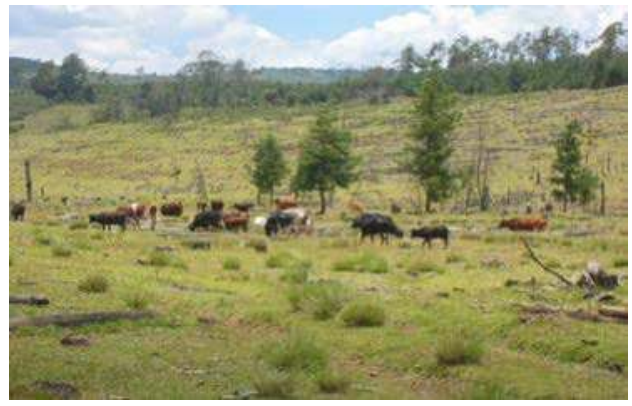

(a)

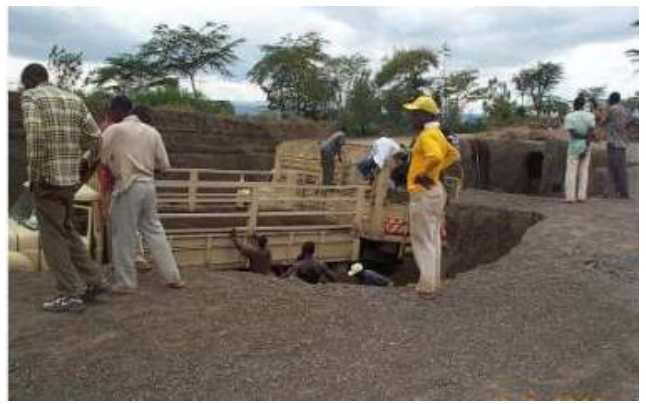

(b)

Fig. 7. (a): Cleared forested presently used for grazing in Nessueit area (Photo taken in 2005 by Kundu) (b): Sand Harvesting at Baruti area near Lake Nakuru (Photo taken in 2009 by Kundu).

In eastern Mau, more than one-half of the cropland is set aside for subsistence farming. Measures such as contour ploughing and conservation tillage that proved effective in soil and water management have been receiving less and less attention. Consequently, a majority of the land has become susceptible to soil erosion processes with the continued degradation. Coupled with this is deteriorating water quality epitomized by the rising level of dissolved nutrients $\left(\mathrm{NO}_{3}\right.$ and $\left.\mathrm{PO}_{4}\right)$, and eutrophication based processes, especially within Lake Nakuru (Karanja et al., 1986; WWF, 1991; Chemelil, 1995; Shivoga, 2001; Owino et al., 2005).

\section{Land cover conversion patterns}

Previous studies at the Regional Centre for Mapping of Resources for Development (RCMRD) involving time series analysis of satellite based remote sensing data have revealed significant land cover changes in the MFC (www.rcmrd.org) as shown in Figures 8 and 9. Before 1986, the dominant pre-change land cover types were about $75 \%$ of forests, $12 \%$ of woodlands and $13 \%$ of farms. By 1989, the landscape had changed tremendously giving rise to about $60 \%$ of forest and woodland, and $40 \%$ of agriculture and built-up area. Figure 8 illustrates deforestation patterns between 1986 and 2000. It should be noted that the change statistics were obtained from classification of medium resolution spatial datasets. Depending on the degree of spatial aggregation used during processing therefore, it is likely that the dominant land cover types could have been overestimated at the expense of non-dominant types. However, a ground survey carried out in retrospect revealed that the classification trends generally compared well with the reality on the ground. The dominant land cover types during the period were largely agriculture and built-up area as per the classifications. The indigenous knowledge furthermore divulged that the loss of forests were largely through clear-cut and progressive thinning by the local residents. 


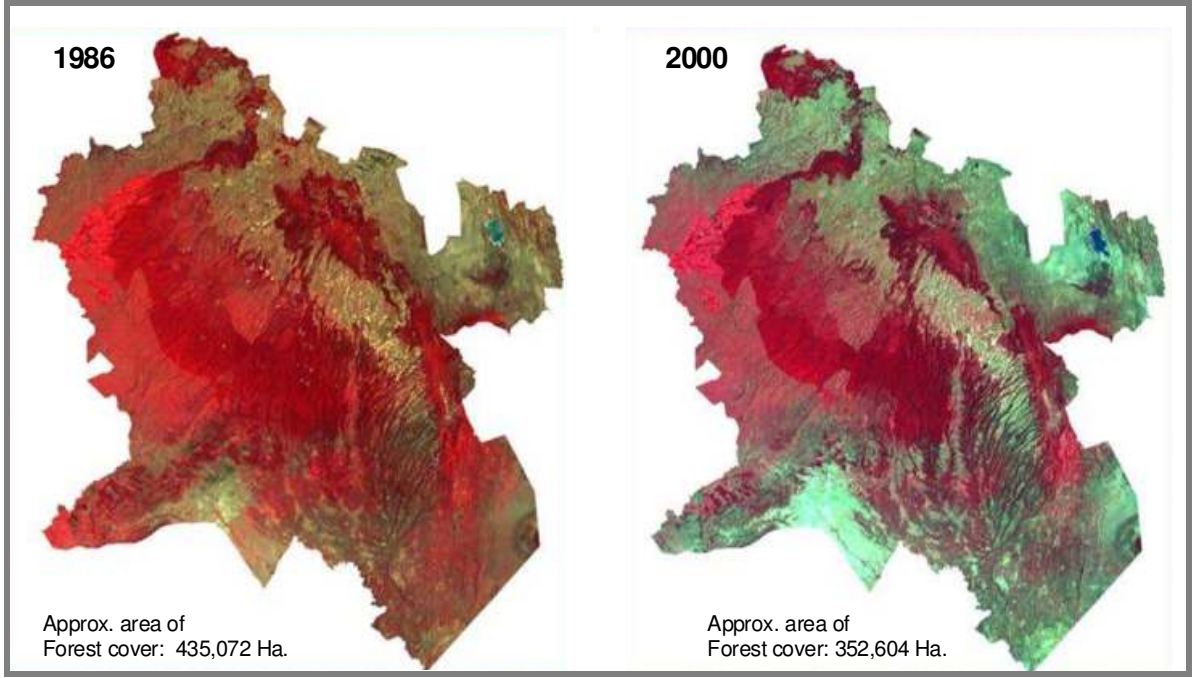

Fig. 8. Deforestation patterns in the Mau complex between 1986 and 2000.

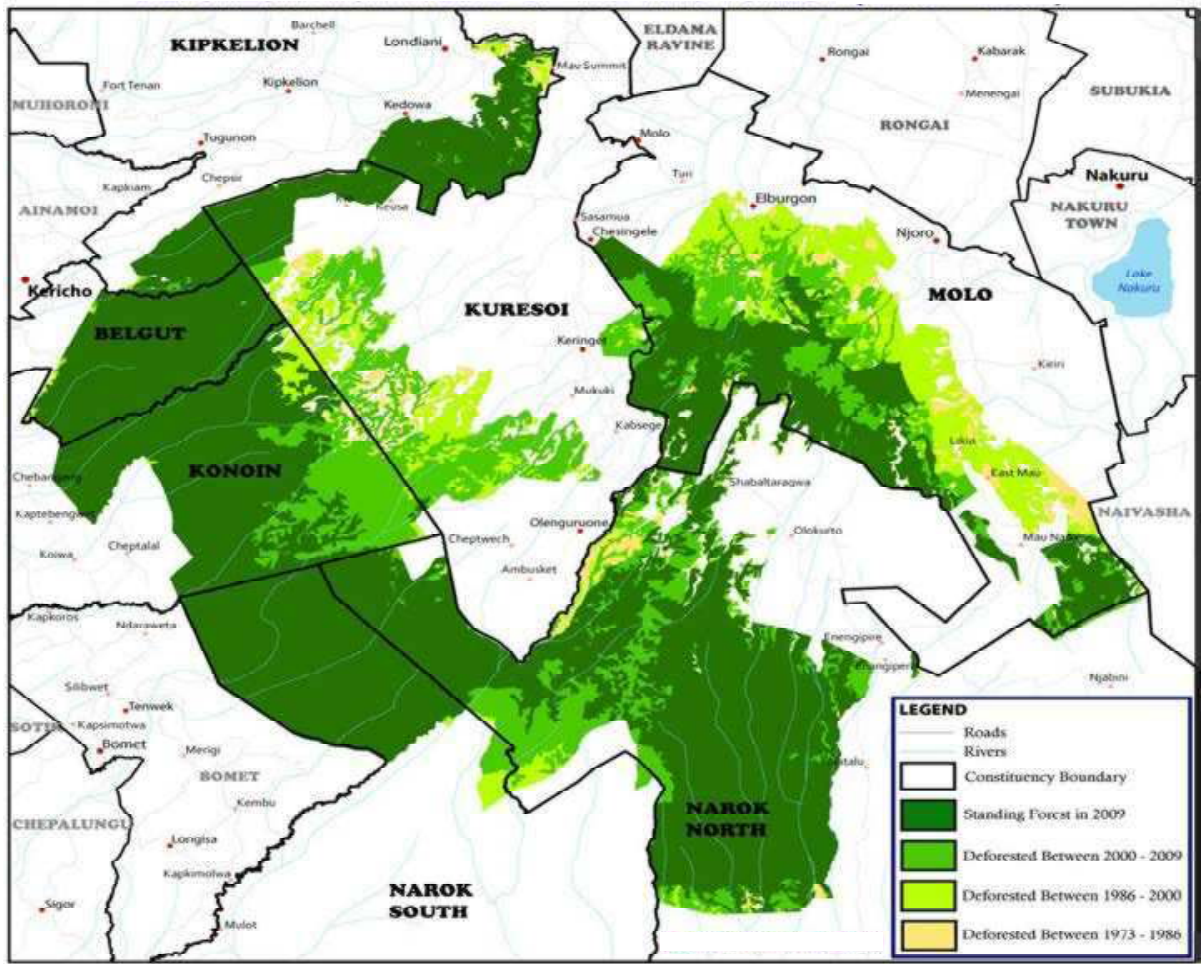

Fig. 9. Deforestation patterns of the MFC located south of Londiani (E. Khamala: 2009) 
Further analysis using Landsat satellite images for the period between 1973 and 2009 have revealed that the section of the forest falling south of Kipkelion and Londiani (Figure 9) stood at about 254,100 hectares in 1973, 249,400 hectares in 1986, 226,100 hectares in 2000 and 179,000 hectares in 2009 (http:/ / kenyafromspace.blogspot.com). Relative to 1973, these figures represent percentage deforestation rates of about $2 \%$ between 1973and 1986, $11 \%$ between 1973 and 2000, and 30\% between 1973 and 2009. From the statistics, it could also be deduced that deforestation rates were highest between 2000 and 2009, when about 47,100 hectares of forest were lost. These results generally conform to ground reality since this period witnessed the highest excisions of the forest owing to the human encroachments and settlements followed by irregular and ill planned forest resource exploitation.

\section{The environmental impact of land use/cover change}

The conversion of forest into agriculture and built-up land in the MFC has led to noteworthy environmental impacts. Generally, increased impervious and hardened surface areas such as roads, parking lots, sidewalks and rooftops diminishes infiltration based processes and, consequently, recharge to the groundwater systems. These processes not only impair the ability of the system to cleanse runoff and protect wetlands, but also amplify the potential for soil erosion and floods, thereby contributing to the degradation of streams and other water bodies. The replacement of forest and woodland by depletive subsistence agriculture has also caused massive inflow of sediments into the nearby Lakes (Ramesh, 1998). The rising nutrient levels from the sediment have affected the growth of blue-green algae (spirulina platensis), which forms the main food for flamingo birds, known to be a major touristic attraction for Lake Nakuru. Apart from reduced revenues associated with ecotourism in the area, the ecological effect of this has been the loss of biodiversity through migration of the birds to other water bodies within the rift valley where complimentary food is available. Conversion from forest to agriculture and grazing land has also disrupted the hydrological cycle of the river drainage basins through increased evaporation and runoff process, especially during rainy seasons.

Generally, low-productivity grass types from natural grassland pastures have lesser leaf area and produce a smaller amount of biomass compared to the forested vegetation. With reduced leaf area and biomass consequent of the land degradation, rainfall interception and surface detention capacity are bound to significantly decrease. This reduces the soil moisture retention capacities, further contributing to the decline in the general evapotranspiration rates $\left(\mathrm{ET}_{\mathrm{o}}\right)$ of the area. Changes in land use may also affect the groundwater recharge of a system. This however, depends on the groundwater recharge area, which may be different from the surface water catchments. However, studies have also shown that logging or conversion of forest to grassland for grazing can result into rising water table as a result of decreased evapotranspiration. In some cases, the water table may fall as a result of decreased soil infiltration from soil compaction and non-conservation farming techniques. If the infiltration capacity is substantially reduced, the long term effect can be severe cases of drought and desertification (Maidment, 1993; Chemelil, 1995). Removal of forest from a catchment can also cause significant hydrologic consequences such as decreased rainfall interception leading to variations in the stream water quality and quantity (Mutua and Klik, 2007; Olang et al., 2011). Research has shown that tree canopies can intercept $10-40 \%$ of incoming precipitation depending on the age, location and density of stand, tree species, rainfall intensity and evaporation rates. Land degradation due to 
forest logging, forest fires and wind damage can therefore have major and long lasting effects upon the canopy characteristics and consequently, overall hydrological response of an area. Clearing of forests can also cause habitat fragmentation, loss of biodiversity and water related pollution problems.

From a macro-scale perspective however, deforestation as a problem to society is still complex in nature. However, there is no question as to whether deforestation affects the climate system dynamics, atmospheric composition and other ecosystem processes. In the tropical regions, observational studies on the effects of land cover conversions on the climate and hydrology of very large basins greater than $100,000 \mathrm{~km}^{2}$ are still scarce. The few large-scale catchment-based studies available have found no consistent relation between land cover degradation and climate changes. The studies further suggests that if appropriate land cover, precipitation, and discharge data were available in time and space, then perhaps it would be possible to determine whether the impact of land cover change across very large catchments is similar to that observed in smaller catchments. Figure 10 illustrates the impact of land cover changes of the Mau on the ecology of river Njoro (a) and Lake Nakuru (b).

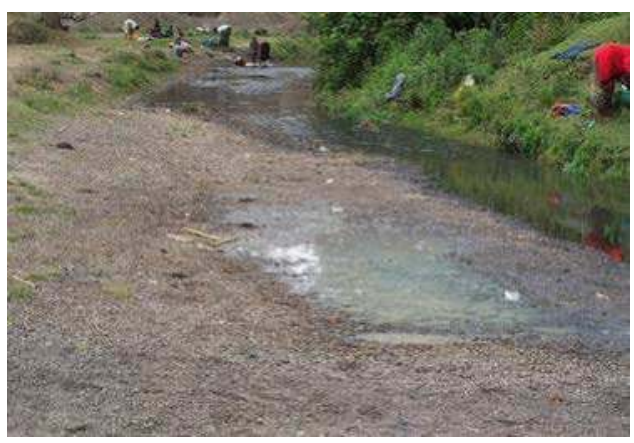

(a)

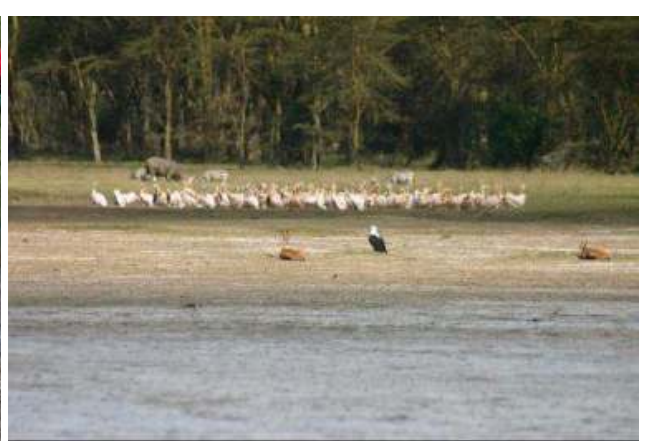

(b)

Fig. 10 (a): Drying river bed at Baruti area (b): Retreating water levels in Lake Nakuru (photos taken by Kundu in 2009).

\section{Environmental conservation strategies}

More recently, the Mau Forest Complex has received considerable attention from local and international organizations due to its ecological significance, which is posing a threat to the whole region. In Kenya, most forest areas are now under the management of the Kenya Forest Service (KFS), which has made substantial steps towards addressing the degradation and deforestation threat to all the major water towers. Among the steps is the new forest policy and law, which were promulgated in 2005. The new law lays emphasis on a participative approach to management of forest resources by all stake holders including local communities and the private sector. A further step is the creation of the Task Force for the Mau Forest Complex (TF-MFC) under the office of the Prime Minister of Kenya, with the mandate to recommend strategies for restoring the forest complex in line with Vision 2030. A very important and urgent scheme is the reforestation and restoration through tree planting as shown in Figure 11. Such activities are organized by the concerned 
governmental chief officers, in collaboration with environmental non-governmental organizations and international organizations.

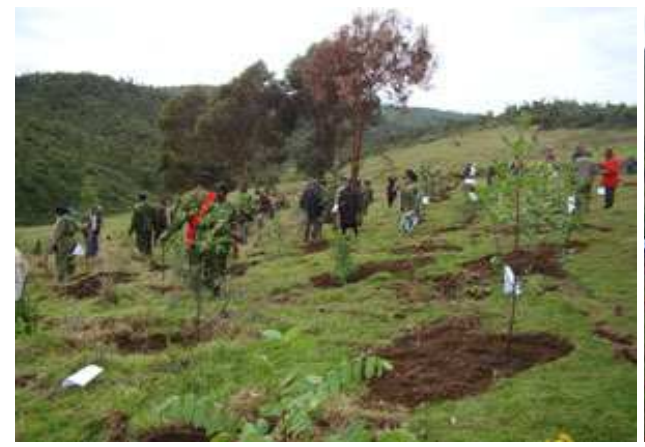

(a)

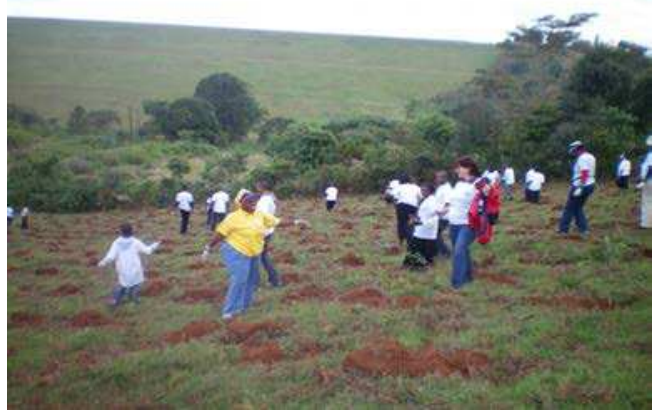

(b)

Fig. 11. (a): Restoration of the Enderit Block of the Eastern Mau Forest Reserve (b): Tree planting to restore the forest covers (Photo taken by Kundu in 2010).

A number of international and sub-regional organizations are involved in the conservation and rehabilitation planning. The major international programme is under the UNEP/DEWA, which is also involved in the assessment of the threats to critical montane forests in East Africa including Mt. Kenya, Aberdare range and Mt. Kilimanjaro. Other organizations which have shown interest, directly or indirectly, include the Africa Convention for the Conservation of Nature and Natural Resources (2003), East Africa Community Treaty (1999), Convention on Wetlands of International Importance Especially as Waterfowl Habitat (Ramsar Convention, 1971), Convention on Biological Diversity (1992), International Tropical Timber Agreement (1983, revised 1994) United Nations Forum on Forests, Intergovernmental Authority on Development (IGAD), Johannesburg Plan of Implementation of the World Summit on Sustainable Development (WSSD), Lake Victoria Protocol (2003), Protocol for Environment and Natural Resources, The United Nations Framework Convention on Climate Change (1992), the World Heritage Convention (1972), the United Nations Convention to Combat Desertification (UNCCD) (1994); the Convention on International Trade in Endangered Species (CITES, 1973), The United Nations Convention to Combat Desertification (UNCCD) (1994), The Nile Basin Initiative (NBI) amongst others. So far under the TF-MFC mandated with co-coordinating the rehabilitation planning of the Mau ecosystem, a number of strategic options have been proposed and realized, in part. The major key interventions were categorized into three phases. Phase 1 involves short term options achievable within the first three years. Phases 2 and 3 involve medium and long term interventions aimed at consolidating the management efforts for sustainability reasons. Among the key interventions, the first and second phases include:

- Development of effective institutional framework and strategic Management Plan

Under this framework, a Mau Forests Complex Authority (MFCA) was to be established to coordinate and oversee the management of the complex. The authority was to be guided by board of directors comprising representatives of the main stakeholders, including the economic sectors directly dependent on the goods and services of the Mau Forests Complex such as water, energy, tourism and wildlife, agriculture and forestry. Ecological 
requirements, in conformity with the needs of existing strategic plans, including for Vision 2030 were to be integrated in the development plan. The current status of the Mau ecosystem, including the existing data status for management purposes were to be considered in achieving this. Additionally is the need for assessment studies on the critical catchment areas and biodiversity hotspots, which require immediate and appropriate conservation strategies.

- Boundary surveys, issuance of title deeds and monitoring and enforcement

This was to involve the demarcation of the legal boundaries and assessment of the critical water catchment areas, assessment of vegetation cover status and biological diversity hotspots in the MFC. Furthermore was the need for routine monitoring to prevent new encroachment, charcoal burning and tree felling that could further attenuate degradation process. Demarcation and fencing of hydrological and biological hotspots or where significant human-wildlife conflicts could occur was hence imperative in this context.

- Relocation, resettlement and livelihood support and development

This activity involved the relocation of all people living in the demarcated protected forests. In the event of resettlement thus, the government was to provide alternative land and funds for the development of the new lands, and livelihoods, while taking into consideration vulnerability of the people within the locations. Immediate livelihood support including water, food, shelter and energy were hence required for the families relocated from the complex to lessen the resentment felt by those aggrieved by their relocation.

- Public awareness and community sensitization

The activity was mainly to address the needs of the local communities living around the forest. The restoration process was to be done in consultation with local communities, who were to benefit both through directly employment opportunities and/or indirectly through ecosystem services including water provision through a restored ecosystem. Sustainable livelihood options in the forest, with particular emphasis on employment opportunities and natural resource based income generating activities were to be explored. This was to include, but not limited to, raising most of the required seedlings for rehabilitation, with the balance being produced through institutional nurseries through technical support by private and international organizations.

\section{Conclusions}

The negative environmental impacts on the MFC, have reached crisis level. Presently, the riparian communities and the Kenya government through key economic sectors that directly depend on goods and services of the region are paying the price of over three decades of negligence and improper land use management. The ongoing restoration efforts, including educating the general public about the need for sustainable environmental conservation in such areas is highly essential and should be sustained. It is imperative that the restoration and rehabilitation efforts are fortified through integration with potential socio-economic activities that can support the survival of the riparian rural communities. Exploring the role of eco-tourism, in relation to natural forested ecosystem, followed by putting in place appropriate and sustainable management framework are hence important in this respect. In order to further support the rural communities it is crucial to initiate long-term agro-forestry based practices such as production of sustainable wood products, and non-timber products such as medicinal plants and honey for commercialization purposes. 
Also, worth mentioning as a fundamental aspect of the conservation would be the unavoidable role of continued research in the region. Further studies that go hand in hand with the restoration and rehabilitation process would be a key support tool that enables necessary and appropriate adjustment as need arises. Evaluating the interactions of the rehabilitated forest ecology in relation with the biological and hydrological systems will be important at every stage. With the increasing advancement in RS techniques, future research activities aimed at exploring new and innovative methods for environmental monitoring and management are also imperative in this respect. Other studies related to carbon sequestration to defer the effects of global warming through Reduced Emissions associated with Deforestation and Degradation (REDD) are also necessary. Considering that land degradation due to anthropogenic causes still remains a major threat to ecosystems and natural resource sustainability in Kenya, successful rehabilitation of the Mau Forest Complex will offer a good prototype that can be studied and possibly emulated across other regions experiencing similar environmental challenges.

\section{Acknowledgements}

The authors would like to acknowledge the support of the relevant authorities at the World Agro-forestry Centre, Regional Centre for Mapping of Resources for Development, Regional Disaster Management Center of Excellence and IGAD - Climate Prediction and Application Centre. Our Sincere gratitude also goes to the editorial team at InTech Publishers for streamlining this work to publication standards.

\section{References}

Baldyga, T. J., Miller, N. S., Driesse, L. K., \& Gichaba, N. C. (2007). Assessing land cover change in Kenya's Mau Forest region using remotely sensed data. African Journal of Ecology, 46, 46-54, doi:10.1111/j.1365-2028.2007.00806.x

Batjes, N. H. \& Gicheru, P. (2004) Soils data derived from SOTER for studies of carbon stocks and change in Kenya (Version 1). World Soil Information (ISRIC) GEF-SOC/VROM project report no. 2004/01 (February 2004).

Borga, M. (2002). Accuracy of radar rainfall estimates for streamflow simulation. Journal of Hydrology, 267, 26-39.

Calder I.R. (1998). Water-resource and land use issues. SWIM Paper 3. Colombo: IIMI

Chemelil, M.C. (1995). The effect of human induced watershed changes on stream flows. PhD Thesis, Loughborough University of Technology, UK.

China, S.S. (1993). Land Use Planning using GIS. Unpublished PhD thesis, University of Southampton

Coppin P., Jonckheere, I., Nackaerts, K., \& Muys, B. (2004). Digital change detection methods in ecosystem monitoring: a review. International Journal of Remote Sensing, 25, 1565-1596.

Corey, J. A. B., Navjot, S. S., Kelvin, S-HP. \& Barry, W. B. (2007). Global evidence that deforestation amplifies flood risk and severity in the developing world. Global Change Biology, 13, 2379-2395, doi:10.1111/j.1365-2486.2007.01446.x

FAO. (1998). Food and Agriculture Organization of the United Nations. Crop evapotranspiration: Guidelines for computing crop water requirements - FAO Irrigation and drainage paper 56, Rome, Italy. 
FAO. (2009). Food and Agriculture Organization of the United Nations. Crop evapotranspiration: Guidelines for computing crop water requirements - FAO Irrigation and drainage paper 56, Rome, Italy.

FAO-UNESCO. (1988) Soil Map of the World, Revised Legend. FAO World Soil Resources report no. 60. Food and Agricultural Organization of the United Nations, UNESCO, Rome, Italy.

Foody, G. M. (2001). Monitoring the magnitude of land cover change on the southern limits of the Sahara. Photogrammetric Engineering and Remote Sensing, 67(7), 841-847. http://www.isric.org/isric/webdocs.Docs/ISRIC_Report_2004_01.pdf.

ISRIC/FAO-UN. (1995). Procedures for Soil Analysis. Technical Paper 9. (5th edition).

Jensen, J. R. (2000). Remote Sensing of the Environment: an earth resource perspective. Prentice Hall series in geographic information science. Upper Saddle River, NJ, USA

Jensen, J. R., 2005. Introductory Digital Image Processing: A Remote Sensing Perspective (3rd edition). Prentice Hall series in geographic information science. Upper Saddle River, NJ, USA.

Karanja, A., China, S. S. \& Kundu, P. M.(1986). The influence of land use on the Njoro River Catchment between 1975 and 1985. In: Soil and Water Conservation in Kenya University of Nairobi, Nairobi, Kenya.

KFWG. (2001). Kenya Forests Working Group. Excision and settlement in the Mau Forest. Report of Kenya Forest Working Group, Nairobi, Kenya, pp.15.

King, L.A. \& Hood, V. L. (1999) Ecosystems health and sustainable communities: north and south. Ecosystem Health, 5, 49-57.

Krajewski, W. F. \& Smith, J. A. (2002). Radar hydrology: rainfall estimation. Advances in Water Resources, 25(8), 1387-1394.

Krhoda, G. O. (1988). The impact of resource utilization on the hydrology of the Mau Hills forest in Kenya. Mt. Resources Development, 8, 193-200.

Kundu P. M., China S. S. \& Chemelil, M. C. (2008). Automated extraction of morphologic and hydrologic properties for River Njoro catchment in Eastern Mau, Kenya. Journal of Science, Technology, Education and Management, 1 (2), 14-27

Kundu, P. M.(2007). Application of remote sensing and GIS techniques to evaluate the impact of land use and land cover change on stream flows: The case for River Njoro catchment in eastern Mau-Kenya. PhD Thesis. Egerton University, Kenya.

Liu, D., Mausel, P. Brondizio, E. \& Moran, E. (2004). Change detection techniques. International Journal of Remote Sensing, 25, 2365-2401.

Maidment, D. R. (1993). Handbook of hydrology. McGraw Hill, New York, San Francisco, USA.

Marcos, H. C., Aurelie, B. \& Jeffrey, A.C. (2003). Effects of large-scale changes in land cover on the discharge of the Tocantins River, Southeastern Amazonia. Journal of Hydrology, 283, 206-217.

Mutua B. M. \& Klik, A. (2007). Predicting daily streamflow in ungauged rural catchments: the case of Masinga catchment, Kenya. Hydrological Sciences, 52(2), 292-304.

Olang L.O., Kundu P. M, Bauer T. \& Fürst, J. (2011). Analysis of spatio-temporal land cover change for hydrological impact analysis within the Nyando River basin of Kenya. Environmental Monitoring and Assessment (Springer), 179, 389-401, doi::10.1007/s10661-010-1743-6. 
Olang, L. O. \& Fürst, J. (2011). Effects of land cover change on flood peak discharges and runoff volumes: model estimates for the Nyando River Basin, Kenya. Hydrological Processes, 25, 80-89, doi:10.1002/hyp.7821.

Olang, L. O. (2009) Analysis of land cover change impact on flood events using remote sensing, GIS and hydrological models. A case study of the Nyando River Basin in Kenya. Dissertation, University of Natural Resources and Applied Life Sciences (BOKU) of Viena, Vienna, Austria.

Owido, S. F. O, Chemelil, C. M., Nyawade, F. O. \& Obadha, W. O. (2003). Effects of Induced Soil compaction on Bean (Phaseolus Vagaries) Seedling Emergence from a Haplic phaeozen soil. Agricultura Tropica. ET subtropica, 36, 65-69.

Owino, J., Owido, S. F. O. \& Chemelil, C. M. (2005). Nutrients in runoff from a clay loam soil protected by narrow grass strips. Journal of Soil and Tillage Research (Elsevier), 88, 116-122.

Pellikka, P., Clark, B., Hurskainen, P., Keskinen, A., Lanne, M., Masalin, K., NymanGhezelbash P. \& Sirviö, T. (2004). Land Use change monitoring applying Geographic Information Systems in the Taita Hills, SE-Kenya. In: Proceeding of the 5th African Association of Remote Sensing of Environment Conference, Nairobi, Kenya.

Rambaldi, G., Muchemi, J., Crawhall, N. \& Monaci, L. (2007). Through the Eyes of HunterGatherer: Participatory 3D modelling among Ogiek indigenous peoples in Kenya. Information Development, 23(2-3), 113-128, doi:10.1177/0266666907078592.

Ramesh, T.(1998). Lake Nakuru Ramsar Project. World Wide Fund for Nature (WWF) (www.aaas.org/international/ehn/biod/thampy.htm)

Refsgaard, J. C. \& Henriksen, H. J. (2004). Modelling guidelines--terminology and guiding principles. Advances in Water Resources, 27, 71-82, doi:10.1016/j.advwatres.2003.08.006

Shivoga, W. A. (2001). The influence of hydrology on the structure of invertebrate communities in two streams flowing into Lake Nakuru, Kenya. Hydrobiologia, 458, 121-130.

Sombroek, W. G.,. Braun, H. M. H. \& van der Pouw, B. J. A. (1980). The explanatory soil map and agro-climatic zone map of Kenya. Report No. E.1, Kenya Soil Survey, Nairobi, Kenya.

World Resources Institute. (2007). Nature's Benefits in Kenya: An Atlas of Ecosystems and Human Well-Being. Washington, DC, USA.

WWF (World Wide Fund for Nature). (1991). Conserving Africa's elephants: current issues and priorities for action. (eds. H.T. Dublin, T.O. McShane and J. Newby), WWF International, 1196 Gland, Switzerland. 


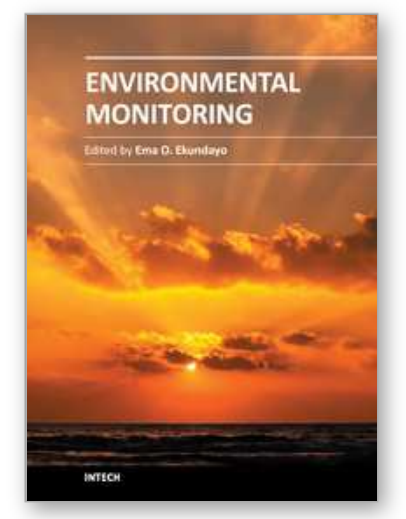

\author{
Environmental Monitoring \\ Edited by Dr Ema Ekundayo
}

ISBN 978-953-307-724-6

Hard cover, 528 pages

Publisher InTech

Published online 04, November, 2011

Published in print edition November, 2011

"Environmental Monitoring" is a book designed by InTech - Open Access Publisher in collaboration with scientists and researchers from all over the world. The book is designed to present recent research advances and developments in the field of environmental monitoring to a global audience of scientists, researchers, environmental educators, administrators, managers, technicians, students, environmental enthusiasts and the general public. The book consists of a series of sections and chapters addressing topics like the monitoring of heavy metal contaminants in varied environments, biolgical monitoring/ecotoxicological studies; and the use of wireless sensor networks/Geosensor webs in environmental monitoring.

\title{
How to reference
}

In order to correctly reference this scholarly work, feel free to copy and paste the following:

Luke Omondi Olang and Peter Musula Kundu (2011). Land Degradation of the Mau Forest Complex in Eastern Africa: A Review for Management and Restoration Planning, Environmental Monitoring, Dr Ema Ekundayo (Ed.), ISBN: 978-953-307-724-6, InTech, Available from:

http://www.intechopen.com/books/environmental-monitoring/land-degradation-of-the-mau-forest-complex-ineastern-africa-a-review-for-management-and-restoration

\section{INTECH}

open science | open minds

\section{InTech Europe}

University Campus STeP Ri

Slavka Krautzeka 83/A

51000 Rijeka, Croatia

Phone: +385 (51) 770447

Fax: +385 (51) 686166

www.intechopen.com

\section{InTech China}

Unit 405, Office Block, Hotel Equatorial Shanghai

No.65, Yan An Road (West), Shanghai, 200040, China 中国上海市延安西路65号上海国际贵都大饭店办公楼 405 单元

Phone: +86-21-62489820

Fax: +86-21-62489821 
(C) 2011 The Author(s). Licensee IntechOpen. This is an open access article distributed under the terms of the Creative Commons Attribution 3.0 License, which permits unrestricted use, distribution, and reproduction in any medium, provided the original work is properly cited. 